\title{
Application of Grey Prediction Model in Rural Informatization Construction
}

\author{
Jing $\mathrm{Du}^{1,3}$, Daoliang $\mathrm{Li}^{2}$, Hongwen $\mathrm{Li}^{1, *}$, and Lifeng Shen ${ }^{2}$ \\ ${ }^{1}$ College of Engineering, China Agricultural University, 17 Tsinghua East Road, \\ P.O. Box 46, Beijing, 100083, P.R. China \\ lhwen@cau .edu.cn \\ ${ }^{2}$ College of Information and Electrical Engineering, China Agricultural University, \\ Beijing 100083, China \\ ${ }^{3}$ China Agricultural University Library, Beijing 100083, China
}

\begin{abstract}
Grey system theory has been widely applied to many domains such as economy, biology, agriculture, control and so on. Based on the theory of grey system, this paper established $\mathrm{GM}(1,1)$ grey predict modeI for the first time to forecast Chinese every hundred rural households owned computers and every hundred rural households owned mobile phone. The predicting results are almost close to the actual values, and this shows that the model is reliable. Finally, these models are used to forecast the two factors in the future years. The research provides a new seientific method for predicting rural informatization development.
\end{abstract}

Keywords: Rural informatization, GM(1,1) model, grey theory.

\section{Introduction}

Agriculture and rural informatization is an important component of the national economy informatization. Setting up prediction model is very significant for the social and economic systems. Because rural informatization is a society-economynature complex system, there are many kinds of factors afflecting rural informatization level, and it is difficult to confirm all influencing factors. Besides, some factors are indefinite, some are definite but difficult to be described quantitively and some are quantified but they may have randomness. Therefore, we can think that rural informatization is a gery system.

Since grey system analysis method has fine adaptability to actual situation when information is incomplete, rural informatization system can be studied using grey theory, among which single sequence one order $\operatorname{GM}(1,1)$ model can be applied. The following work will introduce the principle of grey topological forecast and a grey predicting model is set up. This model can be fully processed at a quantity level on the basis of history data to realize a scientific prediction [1].

* Corresponding author. Tel.: +86-10-62737631, Fax: +86-10-62737300. 


\section{The Basis of Grey Prediction Method}

\subsection{Grey System Theory}

The grey theory, developed originally by Deng (1987), is a multidisciplinary and generic theory that deals with systems that lack adequate information and/or have only poor information. The fields covered by the grey theory include systems analysis, data processing, modeling, prediction, decision making and contro1. The grey theory mainly conducts systems analysis with poor, inadequate or uncertain messages. Grey prediction models have been extensively used in many applications [2]. In contrast to statistical methods, the weight of the original series in the time series grey model, called $\operatorname{GM}(1,1)$, has been proven to be more than four. This model is a time series forecasting mode1, encompassing a group of differential equations adapted for parameter variance, rather than a first order differential equation. Its difference equations have structures that vary with time rather than being general difference equations. In addition assumptions regarding the statistical distribution of data are not necessary when the grey theory is applied. The accumulated generation operation (AGO) is one of the most important characteristics of the grey theory, and its main purpose is to reduce the randomness of data. In fact, functions derived from AGO formulations of the original series are always well fired to exponential functions [3-5].

\subsection{Grey GM (1,1 ) Prection Model}

The GM(1,1) model is one of the most frequently used grey forecasting models. This model is a time series forecasting model, encompassing a group of differential equations adapted to parameter variance, rather than a first-order differential equation. Its difference equations have structures that vary with time rather than being general difference equations. Although it is not necessary to employ all the data from the original series to construct the $\operatorname{GM}(1,1)$ model, the weight of the series must be more than four. In addition, the data must be taken at equal intervals and in aconsecutive order without by passing any data. The $\mathrm{GM}(1,1)$ model constructing process is described below [4]:

Denote the original data sequence by

$$
X^{(0)}=\left(X^{(0)}(1), X^{(0)}(2), \cdots, X^{(0)}(n)\right)
$$

The AGO formation of $X^{(0)}$ is defined as:

$$
X^{(1)}=\left(X^{(1)}(1), X^{(1)}(2), \cdots, X^{(1)}(n)\right)
$$

Where

$$
X^{(1)}(1)=X^{(0)}(1) \text { and } X^{(1)}(k)=\sum_{m=1}^{k} X^{(0)}(m), \quad k=1,2, \cdots, n
$$

The GM(1,1) model can be constructed by establishing a first-order differential equation for $X^{(1)}$ as: 


$$
\frac{d X^{(1)}}{d t}+a X^{(1)}=\mu
$$

Where, $\alpha$ is the grey coefficient, $\mu$ is the grey control parameter.

If the estimating parameter vector 5 is defined as:

$$
\hat{\alpha}=\left[\begin{array}{l}
a \\
\mu
\end{array}\right]
$$

And it use the least square method,

$$
\hat{\alpha}=\left[B^{T} B\right]^{-1} B^{T} Y_{n}
$$

Then, the solution of Eq.(4) can be obtained by using the least square method. That is,

$$
\hat{X}^{(1)}(k+1)=\left(X^{(0)}(1)-\frac{\hat{\mu}}{\hat{\alpha}}\right) \mathrm{e}^{-\hat{\alpha} k}+\frac{\hat{\mu}}{\hat{\alpha}}, k=1,2, \cdots, n
$$

Where

$$
\hat{\alpha}=[\hat{\alpha}, \hat{\mu}]^{T}=\left[B^{T} B\right]^{-1} B^{T} Y_{n}
$$

And

$$
B=\left[\begin{array}{cc}
-\frac{1}{2}\left[X^{(1)}(1)+X^{(1)}(2)\right] & 1 \\
-\frac{1}{2}\left[X^{(1)}(2)+X^{(1)}(3)\right] & 1 \\
\vdots & \vdots \\
-\frac{1}{2}\left[X^{(1)}(n-1)+X^{(1)}(n)\right] & 1
\end{array}\right]
$$

And

$$
Y_{n}=\left[\begin{array}{c}
X^{(0)}(2) \\
X_{(0)}^{(3)} \\
\vdots \\
X^{(0)}(n)
\end{array}\right]
$$

$\hat{X}^{(1)}$ is obtained from Eq.(7). Let $\hat{X}^{(0)}$ be the fitted and predicted series,

$$
\hat{X}^{(0)}=\left(\hat{X}^{(0)}(1), \hat{X}^{(0)}(2), \cdots, \hat{X}^{(0)}(n)\right)
$$

Where

$$
\hat{X}^{(0)}=X^{(0)}(1)
$$


Applying the inverse AGO, then have

$$
\begin{aligned}
& \hat{X}^{(0)}(k+1)=\left(\hat{X}^{(1)}(k+1)-\hat{X}^{(1)}(k)\right. \\
& =\left(1-e^{\alpha}\right)\left[\left(X^{(0)}(1)-\mu / \alpha\right)\right] e^{-\alpha k}
\end{aligned}
$$

Where $\hat{X}^{(0)}(1), \hat{X}^{(0)}(2), \cdots, \hat{X}^{(0)}(n)$ are called the $\operatorname{GM}(1,1)$ fitted sequence, while $\hat{X}^{(0)}(n+1), \hat{X}^{(0)}(n+2), \cdots$, are called the $\operatorname{GM}(1,1)$ prediction values.

After the above model is generated and developed, further tests are necessary to underst and the error of forecasted value, as compared to the actual value. To demonstrate the efficiency of the proposed forecasting model, we adopted the residual error test method to compare the actual value and the forecasted value.

Here, Equations (14) and (15) are used to compute the residual error of the Grey forecasting.

$$
\begin{gathered}
\text { Error }=\left|\frac{X(k)-\hat{X}(k)}{X(k)}\right| \\
\text { Average error }=\frac{1}{k} \sum_{k=1}^{n}\left|\frac{X(k)-\hat{X}(k)}{X(k)}\right|
\end{gathered}
$$

\section{Grey Prediction of Rural Informatization Infrastructure}

Based on the characteristics of rural informatization, this paper choose two factors to be predicted, one is every hundred rural households owned computers, the other is every hundred rural households owned mobile phones [6].

Between 2000 and 2008, the every hundred rural households owned computers, the every hundred rural households owned mobile phones in China are listed in Table1.

Table 1. Annual values of the two rural informatization factor between 2000-2008

\begin{tabular}{ccc}
\hline Time & $\begin{array}{l}\text { Every hundred rural households } \\
\text { owned computers }\end{array}$ & $\begin{array}{l}\text { Every hundred rural households } \\
\text { owned mobile phones }\end{array}$ \\
\hline 2000 & 0.5 & 4.3 \\
2001 & 0.7 & 8.1 \\
2002 & 1.1 & 13.7 \\
\hline
\end{tabular}


Table 1. (continued)

\begin{tabular}{lcc}
\hline 2003 & 1.4 & 23.7 \\
2004 & 1.9 & 34.7 \\
2005 & 2.1 & 50.2 \\
2006 & 2.7 & 62 \\
2007 & 3.68 & 77.84 \\
2008 & 5.3578 & 96.13 \\
\hline
\end{tabular}

Based on the data in Table1 and the above principle of grey forecasting, we can get the coefficients in the model through calculation. And then we get grey forecasting model $\mathrm{GM}(1,1)$ of every hundred rural households owned computers and every hundred rural households owned mobile phones.

By using DPS9.05, The predicted values obtained by the proposed $\operatorname{GM}(1,1)$ model and their respective errors are shown in Table 2 and Table 3.

Table 2. Model operation results of every hundred rural households owned computers

\begin{tabular}{|c|c|c|c|c|}
\hline \multicolumn{5}{|c|}{ Model parameter } \\
\hline $\mathrm{a}=0.006531$ & & $b=0.156794$ & & \\
\hline \multicolumn{5}{|c|}{$X(k+1)=-23.680009 \exp (-0.006531 k)+24.006336$} \\
\hline No. & Actual value & Predicted value & Error & $\%$ \\
\hline 2001 & 0.7 & 0.792 & -0.022 & -3.3033 \\
\hline 2002 & 1.1 & 1.2313 & -0.0812 & -7.5411 \\
\hline 2003 & 1.4 & 1.5064 & -0.1066 & -8.4386 \\
\hline 2004 & 1.9 & 1.8782 & 0.11 & 5.7485 \\
\hline 2005 & 2.1 & 1.9008 & 0.2217 & 10.859 \\
\hline 2006 & 2.7 & 2.7173 & 0.1202 & 4.6554 \\
\hline 2007 & 3.68 & 3.989 & -0.1551 & -4.3817 \\
\hline 2008 & 5.3578 & 5.8581 & -0.0911 & -1.7495 \\
\hline \multicolumn{5}{|c|}{ The evaluation of the model } \\
\hline $\mathrm{C}=0.0816$ & \multicolumn{2}{|c|}{ Very good } & & \\
\hline $\mathrm{p}=1.0000$ & \multicolumn{2}{|c|}{ Very good } & & \\
\hline
\end{tabular}


Table 3. Model operation results of every hundred rural households owned mobile phones

\begin{tabular}{|c|c|c|c|c|}
\hline \multicolumn{5}{|c|}{ Model parameter } \\
\hline$a=0.152491$ & & & $\mathrm{~b}=29.303635$ & \\
\hline \multicolumn{5}{|c|}{$X(k+1)=-160.819281 \exp (-0.152491 k)+192.166756$} \\
\hline No. & Actual value & Predicted value & Error & $\%$ \\
\hline 2001 & 8.1 & 7.4016 & 1.3424 & 16.7172 \\
\hline 2002 & 13.7 & 17.1468 & -2.2686 & -16.3302 \\
\hline 2003 & 23.7 & 28.3539 & -2.4442 & -10.3129 \\
\hline 2004 & 34.7 & 36.5123 & -0.6278 & -1.7376 \\
\hline 2005 & 50.2 & 48.8886 & 5.3954 & 10.6858 \\
\hline 2006 & 62 & 56.7101 & 4.0001 & 6.5668 \\
\hline 2007 & 77.84 & 78.187 & 1.9737 & 2.6764 \\
\hline 2008 & 96.13 & 112.1695 & -8.1425 & -8.8905 \\
\hline \multicolumn{5}{|c|}{ The evaluation of the model } \\
\hline $\mathrm{C}=0.1273$ & \multicolumn{2}{|c|}{ Very good } & & \\
\hline $\mathrm{p}=1.0000$ & \multicolumn{2}{|c|}{ Very good } & & \\
\hline
\end{tabular}

We can test the grey model by using the second errors, the average values of absolute values of relative errors respectively are being 0.0816 and 0.1273 , which show that the established grey model have a good accuracy. It can be seen that the simulation results from 2001 to 2008 have a good degree of fitting. This shows that the forecasting model possesses the better forecasting precision and the forecasting resu1ts are believable. Based on these forecasting values, we can ca1culateted annual every hundred rural households owned computers and every hundred rural households owned mobile phones values in China between 2010 and 2013 which is listed in Table4.

Table 4. Predicted values of the two rural informatization factor between 2009-2013

\begin{tabular}{ccc}
\hline Time & $\begin{array}{c}\text { Every hundred rural households } \\
\text { owned computers }\end{array}$ & $\begin{array}{c}\text { Every hundred rural households owned } \\
\text { mobile phones }\end{array}$ \\
\hline 2009 & 7.36 & 115.58 \\
2010 & 9.69 & 159.20 \\
2011 & 12.74 & 217.13 \\
2012 & 16.75 & 293.86 \\
2013 & 22.01 & 395.29 \\
\hline
\end{tabular}




\section{Conclusion and Recommendations}

Based on the grey system theory, two predicting model of rural informatization infrastructure factors have been set up. From the predicting results, its forecasting precision is higher. And the model needs fewer indexes, and thus is simple and convenient to calculate in practical application.

The research results show that when the grey forecasting technology is used in the middle and short-term prediction, this method has higher confidence and can be as a quantitative forecasting method of rural informatization infrastructure factors.

The study of this paper offers a new method and approach to predict for rural informatization development. But the establishment of grey predicts system is not once and for all. The accuracy of predict result is based on the amount and reliability of information we have had. We think it is essentially accurate and reliable for predicting the next period after a new grey prediction system has been established [7]. We should modify grey parameters in time and establish new prediction model based on the risk of new information we have got. Then the credibility of prediction result can be greatly improved with the new model.

\section{References}

1. Sun, J.: Forecasting model of coal requirement quantity based on grey system theory. Journal of China University of mining \& Technology 11(2), 192-195 (2001)

2. Liu, J., Xue, H., Wu, D.J.: Application of improved grey model in the settlement prediction of roadbed foundation. Geography Technical Engineering 19(2), 59-63 (2005)

3. Deng, J.: Grey system essential method. Huazhong University of Science and Technology Press, Wuhan (1996)

4. Li, J., Wang, B., Zhang, B.: Application of Improved Grey Prediction Model to Petroleum Cost Forecasting Petroleum Science, vol. 3(2), pp. 89-92 (2006)

5. Ma, Q., Cao, J.: Grey forewarning and prediction for mine water inflowing catatrophe periods. Journal of Coal Science \& Engineering(China) 13(4), 467-470 (2007)

6. Qin, X., Zhang, X., Zhang, X.: Study on assessment index system for rural informatization in Beijing. Journal of Beijing Agricultural Vocation College 22(1), 42-46 (2008)

7. Wu, M., Qiu, S., Liu, J., Zhao, L.: Prediction Model Based on the Grey Theory for Tackling wax deposition in oil Pipelines. Journal of Natural Gas Chemistry 14, 243-247 (2005) 